\title{
Entrevista
}

\section{Carlos Alberto Ávila Araújo}

\begin{abstract}
Entrevistador: Marco Antonio de Almeida
Livre-Docente em Ciência da Informação e Documentação pela Universidade de São Paulo - USP, Brasil. Professora do curso de Biblioteconomia e Ciência da Informação da Faculdade Filosofia, Ciências e Letras de Ribeirão Preto da Universidade de São Paulo - FFCLRP/USP, Brasil.

E-mail: marcoaa@ffclrp.usp.br
\end{abstract}

Carlos Alberto Ávila Araújo é formado em jornalismo e possui mestrado em comunicação, mas há muitos anos trilha as sendas da Ciência da Informação. Tornou-se doutor em Ciência da Informação pela UFMG em 2005, e realizou períodos de pós-doutorado em Portugal, pela Universidade do Porto (2011) e na Espanha, pela Universidad de Salamanca (2019). Atualmente é professor-associado da Escola de Ciência da Informação da Universidade Federal de Minas Gerais, da qual foi diretor entre 2014 e 2017. Também foi vice-presidente da ANCIB - Associação Nacional de Pesquisa em Ciência da Informação (2016-2018,) e membro da diretoria da ABECIN (Associação Brasileira de Ensino em Ciência da Informação). Atualmente, ocupa a presidência da Associação de Educação e Pesquisa em Ciência da Informação da Iberoamérica e Caribe - EDICIC (2016-2021). Foi Editor Adjunto da revista Perspectivas em Ciência da Informação de 2007 a 2011 e de 2013 e 2015. Pesquisador de múltiplos interesses, seus trabalhos cobrem a epistemologia da Ciência da Informação, as dimensões sociais, culturais e políticas da informação, os estudos de usuários, as práticas informacionais e, mais recentemente, a temática da informação e da pós-verdade. É autor dos livros Arquivologia, Biblioteconomia, Museologia e Ciência da informação: o diálogo possível (2014) e O que é Ciência da informação (2018) 


\section{InCID: Em primeiro lugar, gostaria que contasse um pouco de sua trajetória acadêmica em termos de formação, como chegou à Ciência da Informação e quais foram seus interesses iniciais de pesquisa e atuação nesse campo.}

Carlos Alberto Ávila Araújo: Bem, antes de tudo eu gostaria de agradecer à InCID pela oportunidade dessa entrevista. Acho sempre muito bom conhecer a vida dos pesquisadores, suas escolhas, suas trajetórias. Estimulo muito isso entre meus alunos. Tem um slide que uso nas minhas aulas com os rostos de vários pesquisadores da ciência da informação, e eu o apresento na aula e falo um pouco sobre as pessoas. E, nesse sentido, é uma honra estar aqui "do outro lado", sendo eu a pessoa que se dá a conhecer.

É curiosa essa questão de como cheguei na Ciência da informação, porque há momentos em que sinto que nasci na área. Mas não foi assim. Me formei em jornalismo, comecei a trabalhar como repórter, e também ingressei jovem no mestrado em comunicação social que havia sido criado recentemente na UFMG. Naquela época, final da década de 1990, estavam abrindo várias faculdades particulares no interior de Minas Gerais, e eu acabei indo morar em Caratinga, leste de Minas, onde me tornei professor universitário em 1999.

Aí, ocorreu um fato curioso. A faculdade onde eu trabalhava (se chamava Faculdades Integradas de Caratinga, na época) resolveu fazer um mestrado interinstitucional com a Escola de Ciência da Informação da UFMG. O objetivo era capacitar seus professores que atuavam em cursos diversos como comunicação social, ciências contábeis, computação e serviço social. Então, vários professores da ECI foram a Caratinga ministrar palestras sobre o que era a área. Eu já tinha mestrado, mas resolvi assistir a essas palestras. Até o momento, eu não sabia o que era ciência da informação. Mas gostei muito do que ouvi. Me interessei. Na época, eu estava já pensando no doutorado, sondando áreas e lugares, e então optei por fazer o doutorado em ciência da informação.

Comecei o doutorado em 2002. Foi um período muito intenso. Participei do ENANCIB, que foi em Belo Horizonte, em 2003. Acabei sendo membro da diretoria eleita naquele ano, na condição de membro discente. Dei aula no curso de biblioteconomia, como estágio docente. Fui me envolvendo com a área. Mas ainda pensava que iria voltar para a área de comunicação.

Um dia, numa festa, em maio de 2005, encontrei uma professora da ECI, que eu mal conhecia. Ela me contou que estava aberto um concurso para a área de "usuários da informação". Eu fiquei empolgado com a possibilidade, o tipo de perspectiva de estudo sobre 
os sujeitos, algo meio antropológico, sempre me interessou, e foi minha questão de pesquisa no mestrado, quando estudei pessoas que gostavam de axé music e pagode. Mas eu estava longe de terminar a tese, naquele momento. A professora me aconselhou a terminar a tese rápido, como estava, e fazer o concurso. Pensei dois dias, procurei o meu orientador, e ele concordou que eu defendesse praticamente como estava, para poder fazer o concurso. Foi o que fiz. Deu tudo certo, fui aprovado no concurso, e daí pra frente começou uma longa história na ciência da informação.

Eu comecei a atuar na área de usuários, ministrando disciplinas, pesquisando e orientando. Mas, em 2007, em função da saída de duas professoras da escola, eu acabei assumindo também a área de epistemologia da ciência da informação. Foi a ela que eu me dediquei, mais intensamente, nos anos seguintes, mas nunca abandonei os estudos de usuários.

InCID: Dois tópicos possuem bastante destaque em suas reflexões, o da interdisciplinaridade e o da dinâmica do campo da Ciência da Informação. Como você vê hoje, de um modo geral, essa questão da interdisciplinaridade (e, também, da transdisciplinaridade, multidisciplinaridade)? Há uma mudança efetiva na universidade em relação ao que esses conceitos implicam, ou apenas mudanças superficiais?

Carlos Alberto Ávila Araújo: Como professor de fundamentos da ciência da informação, o debate sobre interdisciplinaridade sempre esteve presente na minha vida. Mas minha avaliação é de que a discussão é muito superficial na área. Ele serve quase que apenas para justificar a presença, na ciência da informação, de pessoas de outras áreas. Acaba havendo uma certa naturalização, e não se aprofunda na questão. Eu diria que a CI não extrai as (boas) consequências epistemológicas da questão da interdisciplinaridade. Então, ao perceber isso, optei por não priorizar o tema em minhas pesquisas.

Contudo, a partir de 2009, por uma questão institucional (a criação dos cursos de arquivologia e museologia na UFMG, em 2009 e 2010, respectivamente), o tema da interdisciplinaridade voltou ao centro dos meus interesses. É que comecei uma pesquisa sobre as relações (ou melhor, as possibilidades de diálogo) entre arquivologia, biblioteconomia, museologia e ciência da informação. A categoria da interdisciplinaridade apareceu com um potencial para ajudar nessa construção. Mas, aí, foi de uma maneira muito específica. Ela veio para proporcionar uma certa reconstrução da ciência da informação, numa perspectiva que 
pudesse acolher os saberes das três áreas. Mas ainda avalio que a noção de interdisciplinaridade tem muito a nos oferecer, e ainda não exploramos todo o seu potencial.

InCID: Em relação à dinâmica do campo da Ciência da Informação, você já escreveu - e polemizou, em alguma medida - acerca da interação entre a CI e outras áreas "clássicas" que possuem uma forte ligação com ela, a saber, a Biblioteconomia, a Arquivologia e a Museologia. Como vê essa relação hoje, na perspectiva acadêmica e na perspectiva institucional/profissional?

Carlos Alberto Ávila Araújo: Pois é, essa questão entrou na minha vida desde um desafio institucional, que era o desejo da nossa Escola de Ciência da Informação de ter os três cursos de graduação (arquivologia, biblioteconomia e museologia) em diálogo e cooperação entre si, e deles com a pós-graduação em ciência da informação. Claro que isso envolveu vários professores. Mas eu, particularmente, resolvi ter essa questão como desafio central de pesquisa. Fiz um pós-doutorado, entre 2010 e 2011, dedicado especificamente a resolver essa questão do ponto de vista epistemológico, isto é, da própria construção do conhecimento científico em cada uma dessas áreas. O que identifiquei é que elas foram atravessadas, mais ou menos nos mesmos períodos, pelas mesmas correntes teóricas das ciências humanas e sociais. Em sua constituição disciplinar, arquivologia, biblioteconomia e museologia têm relações com o renascimento, a modernidade e o positivismo do século XIX. No século XX, as três desenvolveram teorias funcionalistas, críticas, do campo da representação e da perspectiva dos sujeitos. No século $\mathrm{XXI}$, as três áreas vêm sendo marcadas por abordagens interacionistas, praxiológicas, globalizantes, mediacionais. São essas perspectivas que estão aptas ao diálogo com a ciência da informação. Mas não a ciência da informação que se desenvolveu nas décadas de 1960 e 1970, e que continua hegemônica em países como os Estados Unidos, voltada para uma abordagem operacional, de eficácia. A ciência da informação convocada para esse debate é a que está em sintonia com abordagens contemporâneas, marcadas por uma perspectiva pragmática, intersubjetiva, sociocultural, expressa em teorias como a dos regimes de informação, da ética intercultural da informação, da análise de domínio, das humanidades digitais.

Mas claro que o problema não se resolve assim, com perspectivas epistemológicas. Os campos científicos são compostos por pessoas que possuem interesses, estratégias, alianças, egos, e que disputam recursos, prestígio, espaço. Assim, existem muitos movimentos de 
levantamento de fronteiras entre as áreas, alguns deles válidos (relativos, por exemplo, ao respeito à especificidade de cada área, à história de cada área) mas outros que são mais resultado de lutas políticas do que de argumentos científicos. O mesmo se passa no campo profissional. Arquivistas, bibliotecários e museólogos são profissionais que atuam no campo da cultura, da educação, da história, dos direitos humanos. É claro que todos ganham quando existem políticas culturais, políticas educacionais boas. Há um compartilhamento de interesses e objetivos. Mas há também uma disputa por mercado de trabalho, por visibilidade, por postos hierárquicos. Essas disputas por vezes dificultam ou inviabilizam ações de cooperação, de parceria. Mas eu avalio com muita tranquilidade tais processos, porque eles existem em todas as áreas, na saúde, nas ciências exatas, nas áreas gerenciais. Os diálogos avançam e recuam conforme os problemas vão surgindo, vão sendo resolvidos, outros aparecem.

\section{InCID: Outro esforço empreendido por você reside na construção de um pensamento} informacional ibero-americano, tanto na perspectiva teórica quanto na perspectiva de uma articulação internacional de instituições e pesquisadores. Poderia nos contar mais?

Carlos Alberto Ávila Araújo: Eu me preocupo com essa questão por vários motivos. Primeiro, por ter assumido a presidência da EDICIC, a Asociación de Educación e Investigación en Ciencia de la Información de Iberoamérica y el Caribe, desde 2016. Essa associação tem uma história importante de construção de espaços de discussão em seus congressos e de estímulos a parcerias e projetos interinstitucionais. Ali se pode verificar a riqueza de abordagens, teorias, modelos e metodologias desenvolvidas pelos pesquisadores ibero-americanos. Além disso, entre 2010 e 2014 participei da pesquisa "Un análisis teórico-epistemológico de la Bibliotecología y Estudios de la Información - Unidad en la diversidad: Bibliotecología, Documentación y Ciencia de la Información”, coordenada pelo professor Miguel Ángel Rendón Rojas, da Universidad Autónoma de México, junto a pesquisadores de vários países da IberoAmérica. Hoje faço parte do Ciibercid, Círculo Iberoamericano de Ciencia de la Información Documental", dedicado à epistemologia da área. Recentemente, em maio desse ano, fizemos nosso IV Seminário, aberto ao público, com presença de pessoas de vários países. Então, nessas pesquisas, nesses espaços, há a possibilidade de conhecer essa diversidade e surge daí a vontade de divulgar isso, até porque os manuais e tratados de ciência da informação normalmente ignoram a produção ibero-americana e se focam apenas na produção dos Estados Unidos e da Europa. 
Aí vem outra questão. A ciência da informação é dominada, mundialmente, pela perspectiva estadunidense, que mantém basicamente a mesma perspectiva da década de 1960: uma perspectiva positivista, operacional, voltada para a busca da eficácia. Ela prioriza o estudo das tecnologias, mas numa perspectiva apologética, promocional, mercadológica. Mas, no âmbito ibero-americano, existe um desejo de construção de outras perspectivas de estudo, e de legitimação dessas perspectivas. A vitalidade da pesquisa na Ibero-América se dá com uma profunda imersão nas ciências sociais e humanas, explorando-se todas as consequências dessa imersão. A perspectiva crítica sobressai enquanto movimento intelectual em direção à realidade informacional, privilegiando-se questões de memória, identidade, patrimônio, emancipação. As tecnologias são estudadas, mas numa perspectiva igualmente crítica, centrada no diagnóstico de suas contradições, suas dimensões geopolíticas, seus usos ideológicos. Há uma sintonia entre essa produção e movimentos contemporâneos como os da decolonização, do multiculturalismo, das epistemologias do sul, da justiça cognitiva.

Então, é preciso consolidar essa abordagem, que as vezes se encontra de forma fragmentada, dispersa, invisível. É preciso dar-lhe legitimidade, é preciso que ela possa dialogar no cenário internacional no mesmo patamar de cientificidade que outras perspectivas. Mas o que se vê, muitas vezes, no cenário ibero-americano, são tentativas de copiar o modelo estadunidense, implementá-lo, e receber como recompensa por isso a certificação por selos ou pertencimento a determinados movimentos. Existem o desejo e a potência para a construção de uma ciência da informação própria, autônoma - daí a expressão "pensamento informacional ibero-americano".

InCID: Um foco que tem despertado a atenção e a manifestação de intelectuais de diversas áreas nos últimos tempos é em torno da disseminação das chamadas fake news e, correlatamente, de discursos anticientíficos, de discursos de ódio e de discriminação. Você também tem produzido trabalhos e intervenções nessa linha, poderia dizer algo a respeito?

Carlos Alberto Ávila Araújo: Esse foi um tema que, eu diria, “foi atrás de mim”. Desde 2017 vejo pesquisadores da nossa área trabalhando com isso, mas eu mesmo não percebi a importância e a centralidade que ele deveria ter. Foi após as eleições de 2018, amplamente dominadas por processos de desinformação, que avaliei o impacto que a informação tem para a consolidação ou a degradação da democracia. Em 2020, com a pandemia, essa questão se agravou, a ponto de estarmos falando, hoje, de uma infodemia. Resolvi eleger, em 2020, esse 
tema como minha prioridade, acompanhando inclusive a percepção da área sobre sua importância. Hoje são muitas pessoas, no Brasil e no mundo, trabalhando com isso.

Meus primeiros esforços de pesquisa, nessa direção, foram os de tentar entender o fenômeno, por meio de suas causas (o negacionismo científico, os vieses cognitivos, a desintermediação da informação, o auge das redes sociais, o sequestro da ideia de verdade do movimento pós-moderno), suas características (os tipos de desinformação, os meios de propagação, a atuação de robôs e clickbaits) e suas consequências (entre as quais a possibilidade de enfraquecimento da democracia e das instituições). Depois, comecei a ver como se poderia desenhar esse fenômeno desde uma perspectiva informacional, identificando suas dimensões técnicas ou físicas (a lógica dos algoritmos dos motores de busca e das redes sociais, o efeito bolha, a popularidade como critério de qualidade), cognitivas (o víes de confirmação, a dissonância cognitiva) e socioculturais (a cultura da pós-verdade). Mais recentemente, passei a me dedicar à elaboração de uma precisão conceitual nesse terreno, buscando definir o que são fake news, fake science, negacionismo científico, testemunho falso, discurso de ódio, teoria da conspiração, desinformação, pós-verdade e infodemia. Temos um campo imenso ainda de pesquisa, sobretudo no que diz respeito a possíveis soluções ou estratégias de combate aos efeitos nocivos da pós-verdade, no plano da responsabilização, da certificação, da competência dos usuários, entre outros.

\section{InCID: Aproveitando o mote da última questão, como você vê o papel da universidade no atual momento? Nesse sentido, como entende a Ciência da Informação nesse âmbito e como vê a formação de profissionais e pesquisadores no atual cenário?}

Carlos Alberto Ávila Araújo: Vivemos um período de crise das instituições, que se verifica em descrédito em relação à política, aos partidos, aos sindicatos, ao judiciário, à democracia e, também, à ciência e à universidade. Claro que essa crise não é igual em todos os países, nem o descrédito é o mesmo em relação a todas essas instituições. Mas assusta, no momento, a quantidade de vídeos, cursos e pregações, algumas ancoradas em teorias conspiratórias, outras em movimentos políticos ou religiosos, atacando a ciência e as universidades, defendendo que são doutrinadoras, alienantes. Em parte, penso que isso se deve a um certo distanciamento das universidades em relação à população, sobretudo aquelas parcelas mais desfavorecidas (mas não só!), que acabam vendo os discursos e teorias científicas como algo distante, elitista, vago. E, na minha visão, parte disso se deve à lógica competitiva atual da ciência. Pesquisadores estão mais preocupados em publicar em periódicos qualificados, em publicar mais do que os colegas 
para obter bolsas e financiamentos, em ter seu programa com nota mais alta do que os outros. Isso gera uma certa lógica "autista", em que os cientistas se voltam para seus interesses e vão ficando alheios ao que se passa à sua volta - exceto quando isso rende a possibilidade de novos artigos. Precisamos valorizar a extensão, precisamos valorizar o diálogo entre cientistas e sociedade, sobretudo nas ciências humanas e sociais, que lidam com preconceitos, ideologias, valores, normas, isto é, elementos que estão presentes no cotidiano das pessoas e que também são "explicados" pelo senso comum e pela religião.

InCID: Para finalizar: quais são seus projetos no momento? E que autores você recomendaria aos leitores para refletir sobre nosso mundo assolado por tantos vírus - do covid19, da desinformação, do negacionismo, do neoliberalismo?

Carlos Alberto Ávila Araújo: Como eu disse, tenho um interesse na consolidação dessa ideia de um pensamento informacional ibero-americano, em estabelecer diálogo com colegas, contribuir para aumentar a visibilidade da nossa produção. Mas, de fato, as questões relativas à infodemia, desinformação e pós-verdade chegaram e se estabeleceram. E penso que elas merecem a máxima atenção. Estamos vendo pesquisadores e profissionais de tantas áreas (ciência política, direito, computação, antropologia, pedagogia, comunicação social) discutindo informação... e qual a nossa contribuição? Penso que precisamos, urgentemente, contribuir no diagnóstico da realidade infodêmica, em entender essa dinâmica da produção, circulação e uso de informações falsas, ajudar a pensar em soluções, em certificação, responsabilização, promoção de competências para atuar nesse cenário.

Junto a isso, eu imagino que é fundamental entendermos o momento que estamos vivendo no Brasil, os valores, as mentalidades - porque estão diretamente relacionadas com as dinâmicas informacionais que estamos vivendo. Em 2018 Bolsonaro foi eleito presidente, e esse fato está vinculado diretamente aos comportamentos e afetos que estamos vivendo, a uma postura diante da democracia, das instituições, de como atuar nas redes sociais. Compreender esse Brasil que elegeu Bolsonaro, e vários políticos como ele para os cargos de governador, deputado, senador, etc, me parece algo fundamental se quisermos entender a realidade informacional brasileira contemporânea. Vou indicar os três livros que estou lendo neste momento. Um deles se chama "Governo bolsonaro: retrocesso democrático e degradação política”, organizado por Leonardo Avritzer, Fábio Kerche e Marjorie Marona. São capítulos de vários pesquisadores brasileiros sobre diversos aspectos do momento político brasileiro com excelentes análises que nos ajudam a entender como fenômenos distintos estão relacionados. 
Outro livro que estou lendo no momento é "Como derrotar o turno tecno macho nazifascismo", de Marcia Tiburi. Ela é uma autora que tem mergulhado fundo nos afetos de parte da população que tem aderido a certas posturas e mentalidades fascistas, com um poder de análise significativo. Por fim, "Guerra cultural e retórica do ódio", de João Cezar de Castro Rocha, faz uma análise de ideias que foram construindo, ao longo das últimas décadas, o cenário "intelectual" que estamos vivendo hoje. Indico esses livros, porque me divido entre leituras da ciência da informação e leituras sobre o quadro político e cultural brasileiro, e acho que são essas leituras que me fazem querer uma ciência da informação efetivamente capaz de contribuir para os desafios que vivemos atualmente. Principalmente no meu caso, que vejo a ciência da informação essencialmente como uma ciência emancipatória!

Entrevista enviada em: maio 2021. 